\title{
A novel mutant allele of Ncx1: a single amino acid substitution leads to cardiac dysfunction
}

\author{
CAROLIEN WANSLEEBEN, HARMA FEITSMA\#, LEON TERTOOLEN\#\#, CARLA KROON, \\ VICTOR GURYEV, EDWIN CUPPEN and FRITS MEIJLINK* \\ Hubrecht Institute, KNAW \& University Medical Center Utrecht, Utrecht, The Netherlands
}

\begin{abstract}
The biological role and structure-function relationship of the $\mathrm{Na}^{+} \mathrm{Ca}^{2+}$ exchanger $\mathrm{NCX} 1$ have been the subject of much investigation. Subtle mutagenesis to study the function of a protein seems only feasible in in vitro systems, but genetic forward screens have the potential to provide in vivo models to study single amino acid substitutions. In a genetic screen in mouse, we have isolated a mutant line carrying a novel mutant allele of the mouse $N c x 1$ gene. In this allele, a point mutation causes the substitution of a highly conserved asparagine residue (N874) with lysine. Accepted models for NCX1 structure propose that the affected amino acid is located in one of the reentrant membrane loops and experiments in vitro have identified N874 as critical for the ion transport function of NCX1. We found severe circulation defects and defective placentation in homozygous $N c x 1^{N 87 K 4}$ mutant embryos, making the phenotype essentially indistinguishable from those of previously described null mutants. By ex vivo analysis, we demonstrated intrinsic functional abnormalities of cardiomyocytes. Western blot analysis and immunohistochemistry demonstrated normal levels and subcellular localization of the altered protein, ruling out the possibility that the abnormalities are a mere consequence of a major disturbance of protein structure. This study confirms and extends studies in vitro indicating the significance of amino acid N874 for the function of the NCX1 protein. It provides an in vivo model for this mutation and demonstrates the potential of forward genetic screens in a mammalian system.
\end{abstract}

KEY WORDS: forward screen, mouse, heart development, $\mathrm{Na}^{+} \mathrm{Ca}^{2+}$ exchanger

\section{Introduction}

$\mathrm{Ca}^{2+}$ flux is pivotal in excitation-contraction coupling in the heart and in other processes (Lytton, 2007). In cardiomyocytes, the sodium calcium exchanger NCX1 has an important role, particularly in extrusion of $\mathrm{Ca}^{2+}$ during relaxation, but also in $\mathrm{Ca}^{2+}$ entry during contraction. NCX1, also known as SLC8A1, is a member of the superfamily of solute carriers. Three Ncx genes encoding structurally highly similar $\mathrm{Na}^{+/} \mathrm{Ca}^{2+}$ exchanger proteins are present in the mouse genome. Ncx2 and Ncx3 are mainly expressed in the central nervous system and skeletal muscle, respectively (Quednau et al., 2004), while Ncx1 is expressed ubiquitously in adult animals, but at much higher levels in heart, brain and kidney. Expression analysis on embryos shows predominant expression in the developing heart as of approximately the 1-somite stage (Koushik et al., 1999). In four different labora- tories knockout lines representing null alleles of Ncx1 were generated (Cho et al., 2000; Koushik et al., 2001; Reuter et al., 2002; Wakimoto et al., 2000). Mouse embryos lacking a functional Ncx1 gene were reported to die around embryonic day (E) 10.5 with striking cardiac abnormalities. Given Ncx1's assumed cardiac function, these data confirmed the expected phenotype, but some controversy regarding the cause of lethality arose when (I) it was reported that a 'cardiac-specific' Ncx1 knockout is viable into adulthood (Henderson et al., 2004); (ii) two groups showed that heart-specific $N c x 1$ expression in transgenic mice rescued the phenotype only to limited extent (Conway et al., 2002; Cho et al., 2003); (iii) Ncx1 was shown to be expressed in the normal

\footnotetext{
Abbreviations used in this paper: : SNP, single-nucleotide polymorphism;
} PECAM, platelet endothelial cell adhesion molecule; E, embryonic day

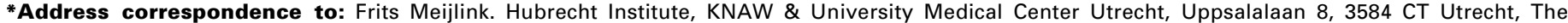

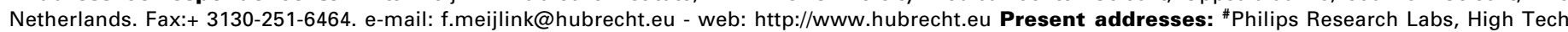
Campus 12a, Eindhoven, The Netherlands. \#Department of Anatomy and Embryology, Leiden University Medical Centre, Leiden, The Netherlands.
}

Supplementary Material (two movies and one figure) for this paper is available at: http://dx.doi.org/10.1387/ijdb.093051cw 
placenta, and placental defects were seen in Ncx1 mutants (Cho et al., 2003).

The topology and the structure-function relationship of the NCX1 protein has been subject of much research. NCX1 is a plasma membrane protein containing nine transmembrane domains, a large intracellular loop that has been directly linked to $\mathrm{Ca}^{2+}$ binding, and two reentrant loops, the $\alpha-1$ and $\alpha-2$ repeats that have been linked to ion transport (Nicoll et al., 1996; Iwamoto et al., 1999; Ottolia et al., 2005).

Here we report a novel mutant allele of Ncx1 that we found in a genetic screen for mutations that disturb early mouse development. We show that a point mutation leading to the substitution of one of the conserved asparagines in the $\alpha-2$ repeat is sufficient to produce an essentially complete loss-of-function phenotype, as compared to published knockout studies. In addition, we demonstrate intrinsic defects of mutant cardiomyocytes, by studying $\mathrm{Ca}^{2+}$ homeostasis and action potential in isolated cardiomyocytes.

\section{Results}

\section{Identification of a mutant line with early-embryonic heart defects}

In the course of an ENU-mediated, phenotype-driven screen for recessive mutations leading to developmental defects (manuscript in preparation), we identified a mutant line that was designated $\mathrm{HI}$ 07. Affected mutant embryos of this line displayed extreme thoracic oedema, inflated branchial arches and abnormal folding of the heart tube (see Fig. 1). Embryos collected at E9.5 or E10.5 had similar morphology and size, but while a heart beat could usually be observed at E9.5, E10.5 embryos never had a beating heart. Yolk sacs of mutant embryos lacked a blood-filled vasculature. Mutant embryos at these stages were obtained with a frequency as expected for an autosomal recessive mutation.

\section{Mapping}

We designed a panel of 192 single nucleotide polymorphisms (SNPs), distinguishing FVB/NJ from C57BI/ 6 DNA. These SNPs are dispersed evenly over the genome, allowing initial crude mapping. Analysis of DNA from 25 mutant embryos and some of their littermates indicated that the gene was located on Chromosome 17, between 75.8-86.1 Mbp. Further mapping using different SNPs in this region (http:// phenome.jax.org/pub-cgi/phenome/mpdcgi?rtn=docs/ home) reduced the candidate region to $78.0-84.5 \mathrm{Mb}$. Among the approximately 55 genes located within this segment is the Ncx1 gene. Since descriptions of homozygous mutant mouse embryos obtained through gene targeting appeared to match the HI-07 mutant, we sequenced the coding regions of Ncx1 in genomic DNA from mutant embryos. This demonstrated a $T>A$ transversion of nucleotide 86 of exon 9 (Fig. 2A) that correlated completely with the phenotype. Because of the mutation, the asparagine residue at position 874 is substituted by a lysine (numbering according to the Ensembl database (www.ensembl.org), Ensembl peptide ID ENSMUSP00000083725). The occurrence of this mutation in combination with a very strong resemblance of the HI-07 mutant phenotype to the described
Ncx1 phenotype basically excludes a noncausal relation between the two. Functional relevance of N874 emerged previously from site-directed mutagenesis studies followed by in vitro assays (Nicoll et al., 1999). From modelling studies, it has been proposed that N874 is located in the membrane as part of the second of two re-entry loops present in the protein (Nicoll et al., 1996, 1999; Iwamoto et al., 1999, 2000; Ottolia et al., 2005; see Fig. 2B).

\section{Ncx1 expression in embryos}

Reports of expression analysis of Ncx1 at early embryonic stages are not entirely consistent, but agree on predominant expression in the heart (Koushik et al., 1999; Wakimoto et al., 2001). Our analyses confirmed expression in the heart at E10.5, which was essentially unchanged in mutant embryos (Fig. 1 D,E).

It is hypothetically possible that the mutation we observed in the $N c x 1 N^{874 K}$ mutant affects the protein in a way that destabilizes it, and/or upsets its targeting to the cell membrane. To address this, we analyzed by Western blot analysis the presence of NCX1 in embryonic hearts. As shown in Fig. 3A, similar levels of 120- and 160-kD NCX1-specific bands were detected in pools of dissected wildtype, heterozygous and homozygous mutant embryos. We also compared expression and subcellular localization in wildtype vs. mutant embryos by immunofluorescence (Fig. 3 B-G). Fig. 3 $B, C$ shows presence of NCX1 protein in the heart of an E9.0 wildtype embryo and similarly in an Ncx1 mutant embryo. Fig. 3D,F shows the plasma membrane localization of NCX1 in wildtype embryos. In mutant cells (Fig. 3E,G) this localization is unchanged. Therefore, the N874K mutation does not bring about a general, unspecific disorder of the NCX1 protein organization. Our attempts to demonstrate expression of Ncx1 in the embryonic vasculature of the placenta were unsuccessful, as the use of the R3F1 antibody led to artefacts in this tissue.

\section{Placental phenotype in Ncx1 mutant embryos}

To investigate the possibility that placentation is disturbed in
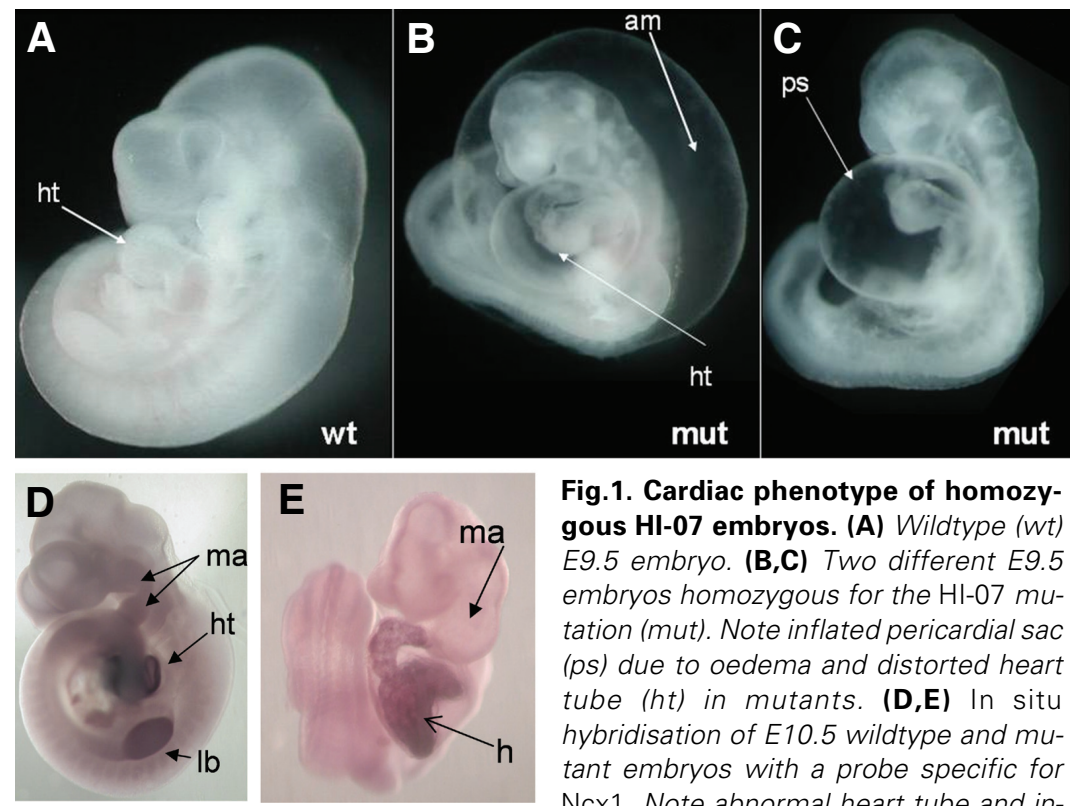

Fig.1. Cardiac phenotype of homozygous HI-07 embryos. (A) Wildtype (Wt) E9.5 embryo. (B,C) Two different E9.5 embryos homozygous for the $\mathrm{HI}-07 \mathrm{mu}$ tation (mut). Note inflated pericardial sac (ps) due to oedema and distorted heart tube (ht) in mutants. (D,E) In situ hybridisation of E10.5 wildtype and mutant embryos with a probe specific for Ncx1. Note abnormal heart tube and inflated mandibular arch (ma) in mutant and heart-specific expression in both embryos. Staining of the limb bud (Ib) may be unspecific. am, amnion. 

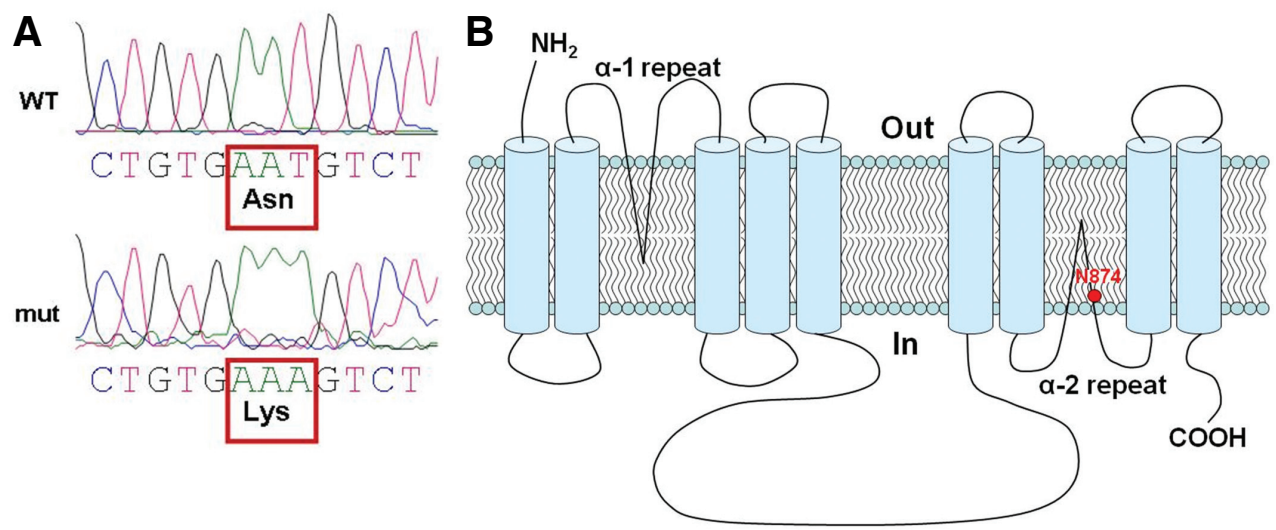

Fig. 2. Identification of $\mathbf{N c x} 1$ mutation in HI-07 mutant embryos. (A) Sequence traces representing the mutation found in the Ncx 1 allele in the HI-07 line. A T to A transversion in the coding region of Ncx1 is evident in DNA from a homozygous mutant embryo, which is predicted to lead at the protein level to replacement of an Asparagine (N874) by a Lysine. (B) Scheme depicting the topology of NCX1 protein as proposed in the literature, in particular references $12,13,15$. The protein contains

9 transmembrane loops, an intracellular loop and two reentrant loops. Orientation of the membrane is indicated by 'Out' and 'In, 'referring to outside and inside the cell. The red dot marked 'N874' indicates the crucial Asparagine mentioned above and discussed in the text.

homozygous mutant $N c x 1^{N 874 K}$ embryos, as was reported for $N c x 1$ knockout embryos (Cho et al., 2000), we analyzed a time series of mutants between E9.0, E9.5 and E10.5. This suggested normal development of the allantois, prior to and including attachment to the chorion. Upon attachment of the allantois, in normal embryos the labyrinth develops because of invasion of the trophectoderm layer by allantois-derived vasculature. The labyrinth layer enables exchange of nutrients and gases between the foetal and maternal circulation (Rossant and Cross, 2001). Comparison of sections of E9.5 placenta from wildtype and mutants revealed that while in the placenta of wildtype embryos the labyrinth could easily be distinguished; in the mutant placenta it had not developed (Fig. 4 A-D). Furthermore, the haemotrichorial layer that separates embryonic and maternal circulation (yellow arrow in Fig. 4B) is seen in wildtype (yellow arrow in Fig. 4C) but not in mutant placenta (Fig. 4D).

To analyze the vasculature of the placenta, we used antibodies against PECAM that specifically label the endothelial lining of the vessels. The results confirm the defective labyrinth development, but do not suggest that vascular endothelium is specifically affected (Fig. 4 E,F).

To better understand the nature of the placenta phenotype, we analyzed expression of a number of markers by in situ hybridization on sections of E9.5 placentas. Expression of eHAND as a trophoblast giant cell marker (Cserjesi et al., 1995), Cdx2 as a trophoblast lineage marker (Beck et al., 1995), and Mash2 as a spongiotrophoblast marker (Guillemot et al., 1994) was essentially normal compared to the wildtype placenta, apart from

Fig. 3. Immunodetection of Ncx1 and Ncx $\mathbf{1}^{\mathbf{N 8 7 4 K}}$. (A) Western blot analysis of pooled embryonic hearts. Hearts were dissected from E9.5 embryos and lysates of identical genotype were pooled. One slot contained $25 \mu \mathrm{g}$ protein from pools of 11-12 hearts. Two NCX1 bands of 120 and $160 \mathrm{kD}$ were detected at similar levels in wildtype (wt), heterozygous (het) and homozygous mutant (mut) material. To control for the amount of protein loaded, the membrane was incubated with an $\alpha$-tubulin antibody ( $\alpha$-tub), as shown below. (B-G) Immunodetection of NCX1 in E9.0 embryos. (B,D,F) Wildtype embryo; $(\mathbf{C}, \mathbf{E}, \mathbf{G})$ homozygous mutant

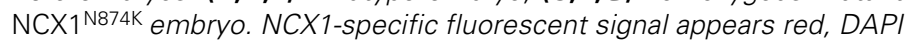
staining for DNA is blue (only in B-E). (B,C) Confocal detection (z-stacks) of low power magnification demonstrates heart-specific expression. (DG) High power magnification (optical sections) reveals plasma membrane localization in both genotypes. differences that are evidently a direct consequence of the abnormal morphology of the mutant placenta (see Supplementary Fig. 1). These results suggest that derivatives of these lineages are present in essentially normal amounts.

\section{Intrinsically affected properties of Nex1 mutant cardiomyo- cytes}

The occurrence of extra-embryonic defects in this Ncx1 mutant opens the possibility that cardiac failure might not be the only or even primary cause of embryonic lethality. We therefore set out to compare intrinsic properties of cardiomyocytes isolated from mutant embryos and their wildtype litter mates. Two key components of excitation contraction coupling were studied, the action potential (AP) and the $\mathrm{Ca}^{2+}$ homeostasis. Hearts from E9.5 normal and mutant embryos were isolated, dissected into small pieces, dissociated enzymatically and replated. After one day of culture, cardiomyocytes from wildtype embryos were contracting regularly and synchronously in small clusters. In contrast, cardiomyocytes derived from mutant embryos were fibrillating and

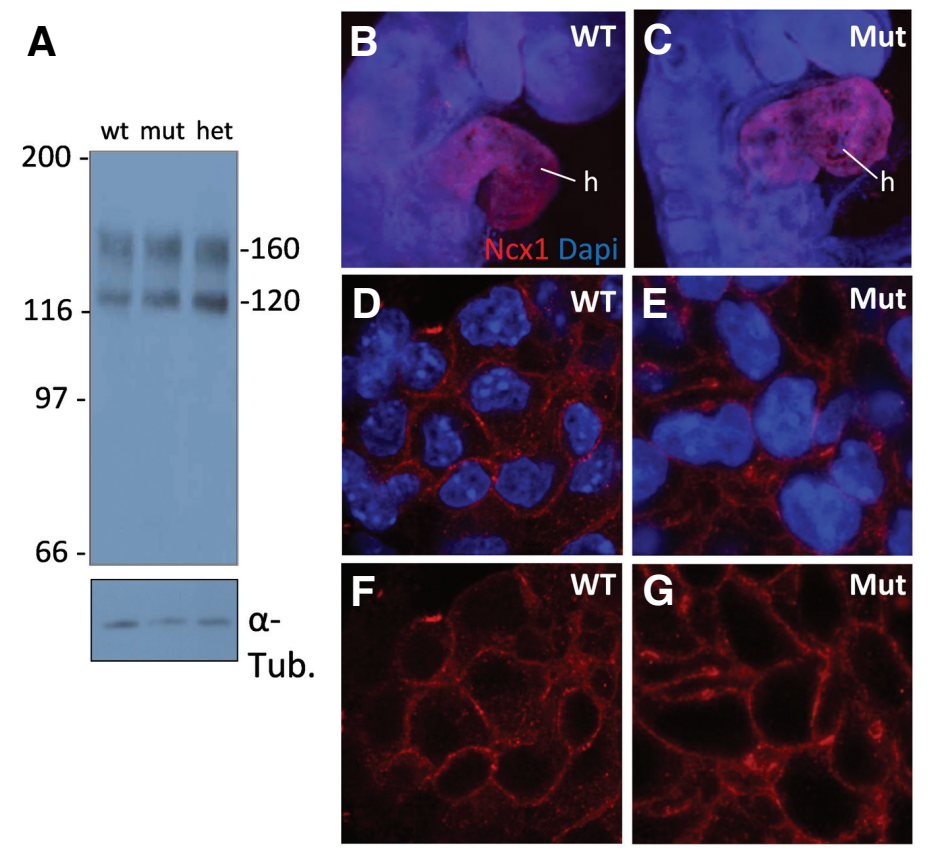



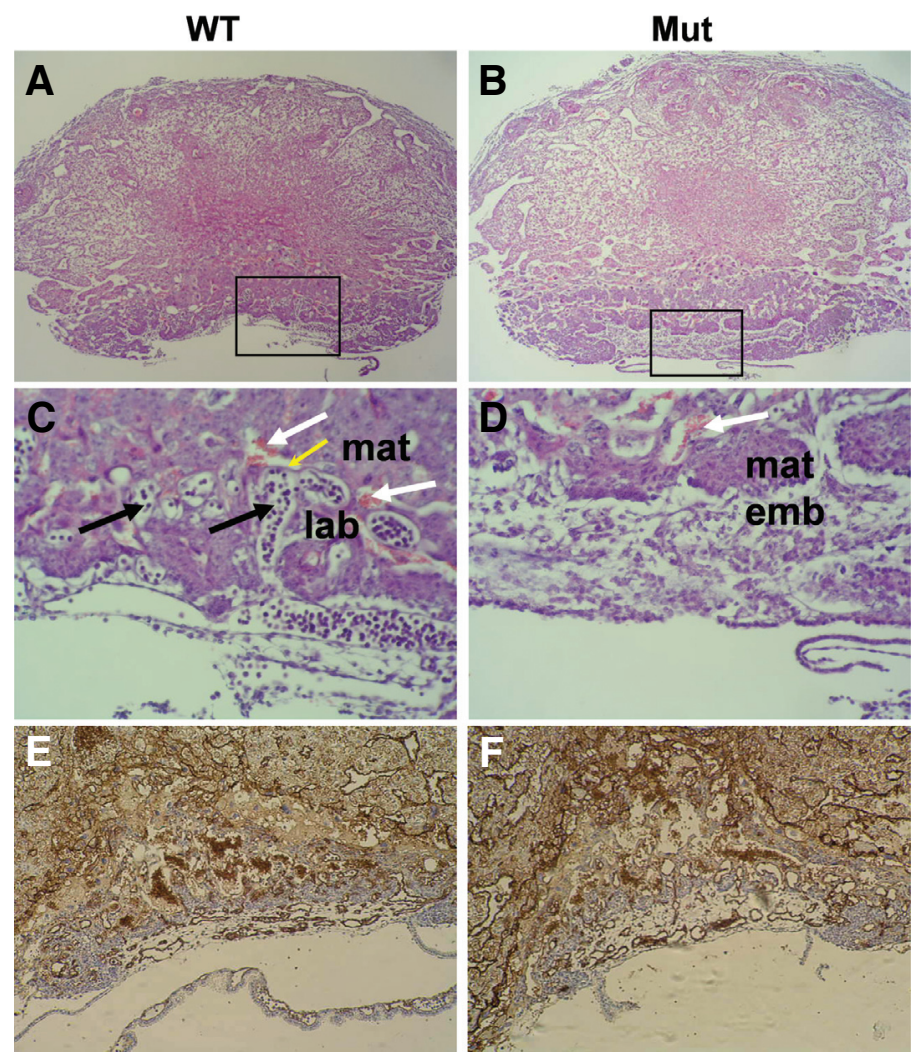

Fig. 4. (Left). Abnormal placentation in HI-07 mutants. (A-D) Haematoxylin and eosin stained sections of E9.5 placentas from wildtype $(\mathbf{A}, \mathbf{C})$ or mutant $(\mathbf{B}, \mathbf{D})$ embryos. Maternal blood appears red and is indicated by white arrows. Embryonic (nucleated) erythrocytes are seen as dark round cells, and are pointed out by black arrows. Labyrinth formation manifests by the penetrance of embryonic blood into the maternal part of the placenta. This occurs in the wildtype, but not in the mutant placenta. In (C,D), 'lab' indicates area of labyrinth; 'mat' and 'emb' indicate areas of maternal and embryonic placenta, respectively. The yellow arrow indicates the thin layer known as haemotrichorial layer that separates maternal and embryonic circulation. This interface was never seen in mutant placenta. (E,F) PECAM staining of sections similar to those of panels (A-D), showing normal expression of this endothelium marker. Mutant (mut) and wildtype (wt) placenta as indicated on top of the figure.

Fig. 5. Calcium transients and action potentials in wildtype vs. mutant cardiomyocytes. (A) Representative calcium transients in fura- 2 loaded, spontaneous beating wild-type black) and $\mathrm{Ncx}^{\mathrm{N} 874 \mathrm{~K}}$ mutant (red) cardiomyocytes. (B) Representative action potentials of spontaneous beating wildtype (black) and Ncx1874K mutant (red) cardiomyocytes.

contracting randomly (see supplementary videos). The $\mathrm{Ca}^{2+}$ transients of $N c x 1^{N 874 K}$ cardiomyocytes were smaller in amplitude and had a lower frequency $(0.53 \mathrm{~Hz})$ than their wild-type counterparts $(1.06 \mathrm{~Hz})$ (Fig. 5A). Although small $\mathrm{Ca}^{2+}$ transients were found, very rarely action potentials were detected, which were never repetitive. In the mutant cells we were able to measure only two prolonged action potentials out of ten recordings (Fig. 5B). These results are consistent with the notion that the Ncx1 $1^{N 874 K}$ mutation causes intrinsic abnormalities in embryonic cardiomyocytes. Clearly, these malfunctions would be sufficient to explain the embryonic phenotype including early lethality.

\section{Discussion}

In addition to identifying novel roles of genes in an unbiased way, a phenotype-based approach involving generation of point mutations is also expected to yield subtly altered mutant alleles of genes. Such mutants may be of interest if they represent hypo-
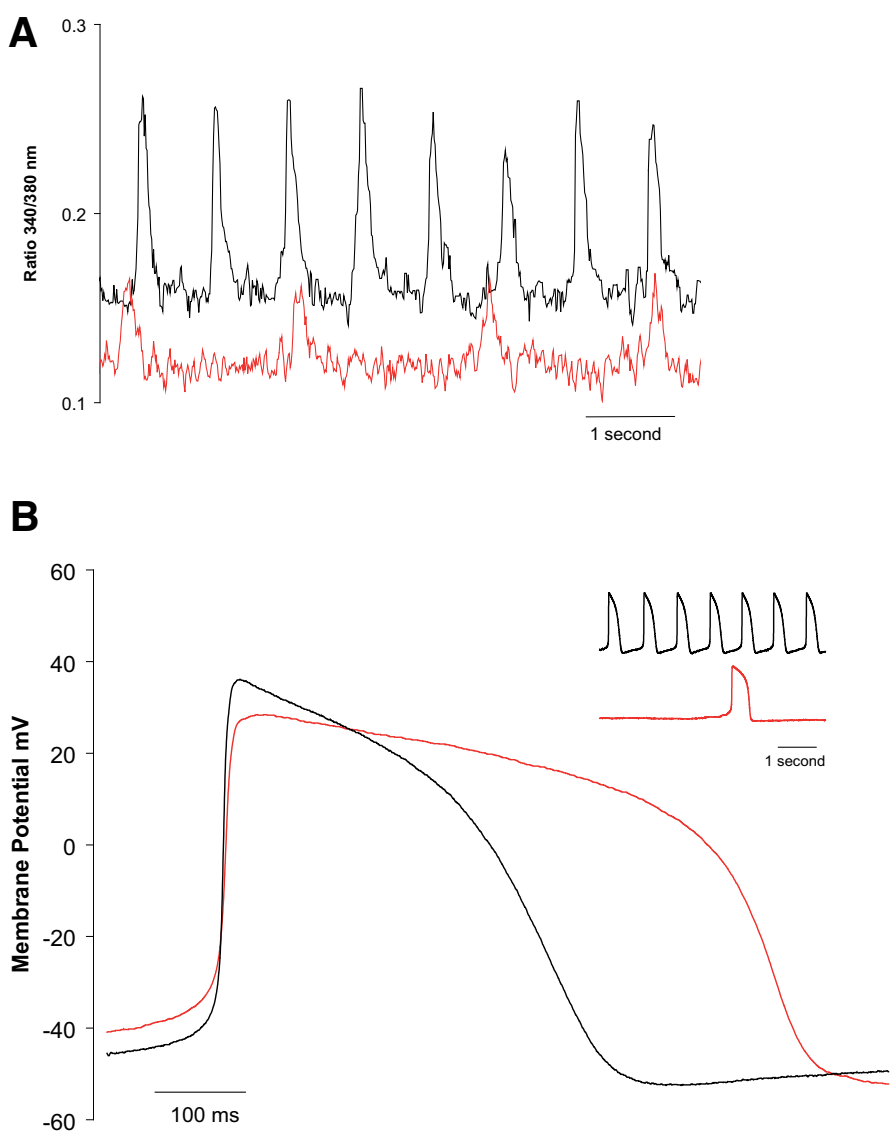
mutants. Koushik et al. (2001) reported total absence of heartbeat in homozygous mutant embryos at all stages (see also Lux et al., 2008 and Rhodes et al., 2008) whereas others (Cho et al., 2000 and Wakimoto et al., 2000) observed at least some contractility in all or some of the mutant embryo hearts. Our observation that mouse embryos homozygous for the mutation retain a heartbeat at E9.5 therefore does not resolve the question as to remaining functionality of the NCX1 $1^{\mathrm{N} 874 \mathrm{~K}}$ protein.

Our ex vivo analyses of mutant cardiomyocytes demonstrate major functional deficits of mutant E9.5 cells that are sufficient to explain early lethality. The essential physiological role of NCX1 in the heart is further emphasized by reports of arrhythmias in zebrafish Ncx1 mutants (Ebert et al., 2005; Langenbacher et al., 2005) where complications of extra-embryonic development do not apply. The doubts that have arisen as to the question whether heart failure is the primary cause of embryonic lethality around E10 were based on survival of a 'heart-specific' knock-out in which, however, only $80-90 \%$ of the cells had lost Ncx1 activity (Henderson et al., 2004). In addition, attempts to rescue the Ncx1 phenotype by expressing Ncx1 under control of an $\alpha \mathrm{MHC}$ promoter failed to compensate more than marginally (Conway et al., 2002; Cho et al., 2003). Although efficacy of the expression construct at the relevant embryonic stages was not demonstrated by these authors, this suggests a potential role of Ncx1 in placental development. On the other hand, since heart failure in the $N c x 1^{N 874 K}$ mutant is already evident at E9.5, and our analyses of cell-specific markers in mutant placenta (Supplementary Fig. 1) showed essentially normal patterns, it is possible that the placental defect we observe is a mere secondary consequence of it, for instance as consequence of delayed development, as has been suggested for a number of mutants (Conway et al., 2003). The lack of vascularization of the yolk sac may also be a consequence of impaired cardiac function. It was recently reported that haemodynamic force is necessary and sufficient to induce vessel remodeling in the mouse yolk sac. The manifestation of the Ncx1 deficiency in our HI-07 mutant in appearance of the yolk sac phenotype strongly resembles what these authors show for Mlc2a knock-out embryos, an immature appearance and failure of remodelling of the capillary plexus. Interestingly however, no labyrinth phenotype has been reported for the Mlc2a mutant (Lucitti et al., 2007).

Iwamoto and co-workers (Iwamoto et al., 1999, 2000) and others studied the structure of dog NCX1 protein. On the topological disposition of $\mathrm{N} 842$ (corresponding to mouse N874), these authors concluded that it is located in the membrane as part of a reentrant loop. Replacement of N842 by cysteine allowed examining its accessibility. It was demonstrated to be chemically accessible from the intracellular membrane surface and possibly also from the outside (Iwamoto et al., 2000). Earlier, functional importance of this amino acid had been revealed by demonstrating that its mutation to aspartate or valine led to decreased exchange activity (Nicoll et al., 1996). Mouse Ncx1 N874 is therefore likely to be a part of the mechanism responsible for ion transport. Interestingly, Iwamoto et al. (2000) showed that replacement of N874 with cysteine did not affect NCX1 performance, whereas subsequent treatment with methanethiosulfonate ethylammonium (MTSEA) did inhibit its activity. MTSEA is a sulfhydryl reagent that converts the neutral cysteine side-chain to a positively charged group resembling a lysine side-chain; there- fore this in vitro experiment resembled the situation resulting from the point mutation in the $N c x 1^{N 874 K}$ mutant.

In conclusion, our analysis of a novel loss-of-function mutant allele encoding an abnormal $\mathrm{NCX} 1^{\mathrm{N} 874 \mathrm{~K}}$ protein substantiates the importance of the conserved asparagine at position 874. By extrapolation of published work in vitro, it is likely that the $\mathrm{NCX} 1^{\mathrm{N} 874 \mathrm{~K}}$ protein is specifically defective in ion transport. While protein levels and subcellular location of the protein remained unaffected, a strong embryonic phenotype was observed in homozygous mutants. Our data establish for the first time in vivo the essential role of this residue and demonstrate the potential power of phenotype-driven genetic screen as an intermediate between gene targeting studies and studies in vitro.

\section{Materials \& Methods}

\section{Identification of mutant}

We identified the HI-07 mutant in the course of a genetic screen for recessive mutations affecting development. This screen will be described in more detail elsewhere. Briefly, C57BL/6 mice were injected three times with one-week intervals with $60-80 \mathrm{mg} / \mathrm{kg}$ bodyweight of $\mathrm{N}$-ethyl- $\mathrm{N}$ nitrosourea and crossed with FVB/N mice. Founders were crossed with their daughters and embryos, which were potentially homozygous for ENU-induced mutations, were examined at E10.5.

\section{Mapping procedures}

We designed a SNP panel for approximate mapping of mutations from our screen. SNPs were chosen to be equally spread along all chromosomes excluding $Y$ and to be polymorphic between $\mathrm{C} 57 \mathrm{BL} / 6$ and FVB/N. $10 \mu \mathrm{l}$ of PCR product was diluted with $25 \mu \mathrm{l}$ water and $1 \mu \mathrm{l}$ was used as template for the sequencing reactions. Sequencing reactions, containing $0.25 \mu$ l BigDYE (v1.1; Applied Biosystems), $3.75 \mu \mathrm{l} 2.5 x$ dilution buffer (Applied Biosystems), and $0.4 \mu \mathrm{M}$ gene-specific primers in a total volume of $10 \mu \mathrm{l}$, were performed using cycling conditions recommended by the manufacturer. Sequencing products were purified by ethanol precipitation in the presence of $40 \mathrm{mM}$ sodium acetate and analyzed on a 96capillary 3730XL DNA analyzer (Applied Biosystems). Sequences were analyzed for the presence of polymorphisms using Polyphred (Thurneysen et al., 2002). Primers for PCR amplification and sequencing were designed using the Ensembl genome database (http://www.ensembl.org).

\section{Western blot analysis}

E9.5 mouse embryos were harvested in PBS; hearts were dissected and separately lysed in $5 \mu$ I RIPA buffer ( $50 \mathrm{mM}$ Tris- $\mathrm{HCl}, \mathrm{pH} 7.5,150 \mathrm{mM}$ $\mathrm{NaCl}, 1 \% \mathrm{NP} 40,0.5 \% \mathrm{DOC}, 0.1 \% \mathrm{SDS}$ ) including protease inhibitors. After genotyping, 11 or 12 hearts of every genotype were pooled, and protein concentrations of the pools were determined using the Bicinchoninic assay Kit (Sigma-Aldrich). 2x Laemmli sample buffer was added to $25 \mu \mathrm{g}$ protein and the mixture was heated at $70^{\circ} \mathrm{C}$ before loading. Polyacrylamide gel electrophoresis (PAGE) and Western blotting were performed according to standard procedures, including use of the ECL system for luminescence detection. Mouse-anti-NCX1 (R3F1, Swant, Bellinzona, Switzerland) was diluted 1:500 in 5\% milk powder in TBS-Tween blocking solution. The NCX1-specificity of this antibody has been described (Van Nes et al., 2006). After stripping, the blot was incubated with mouse-anti$\alpha$ tubulin (1:2000 in TBS-Tween, t6199, clone DM1A, Sigma-Aldrich). The secondary antibody used was HRPO-coupled anti-mouse (BDbiosciences).

\section{Immunohistochemistry}

Embryos were dissected in PBS and fixed overnight in $4 \%$ paraformaldehyde (PFA) and dehydrated by increasing Methanol concentrations to $100 \%$ for storage at $-20^{\circ} \mathrm{C}$. After rehydration, embryos where 
blocked in PBS, $0.1 \%$ Triton X-100-1 \% BSA for 1 h and incubated with 1:500 mouse-anti-NCX1 (R3F1, Swant, Bellinzona, Switzerland). After washing with PBS containing $0.1 \%$ Triton $X-100$, embryos were incubated with the secondary antibody (Cy3-goat-anti-mouse 1:250; Jackson Immunological). Nuclei were stained with DAPI (Invitrogen). Fluorescence was analyzed by using a Leica TCS SPE confocal microscope and the Leica Application Suite software. PECAM-staining has been described (Van Nes et al., 2006).

\section{Preparation of dispersed cardiomyocytes}

Single cardiomyocytes were prepared essentially as described (Maltsev et al., 1994). In brief, embryonic hearts were dissected, washed and then transferred to collegenase-containing buffer and incubated for $45^{\prime}$ at $37^{\circ}$ C. Tissue was then transferred to KB buffer (Maltsev et al., 1994) and shaken at room temperature for 1 hour at $100 \mathrm{rpm}$. Small amounts of tissue were dispersed by pipetting up and down and transferred to 12-well plates containing gelatin coated cover slips and hES medium (Braam et al., 2008).

\section{Calcium measurements}

The equipment used consisted of a Leica DM R upright microscope (Leica-Microsystems Wetzlar GmbH, Germany) equipped with an UV 40x water-immersion objective ( $0.9 \mathrm{NA})$ and a temperature-controlled specimen holder. Measurements were done in a buffer containing $145 \mathrm{mM}$ $\mathrm{NaCl}, 5 \mathrm{mM} \mathrm{KCl}, 2 \mathrm{mM} \mathrm{MgCl}$, $2 \mathrm{mM} \mathrm{CaCl}$, $10 \mathrm{mM}$ HEPES, $10 \mathrm{mM}$ glucose and $0.5 \%$ bovine serum albumin, at $33^{\circ} \mathrm{C}$. The cells were labelled for 15 minutes at $37^{\circ} \mathrm{C}$ with $10 \mu \mathrm{M}$ fura2-AM (Invitrogen, Molecular Probes). The light from two excitation monochromators (SPEX fluorolog SPEX Industries EDISON, N.J, USA) was rapidly alternated between 340 $\mathrm{nm}$ and $380 \mathrm{~nm}$ and the ratio of the emission signals (wave length $505 \mathrm{~nm}$ ) was recorded.

\section{Expression analysis}

In situ hybridization on whole mounts or sections was as described previously (Kuijper et al., 2005). Probes were previously described (Van Nes et al., 2006) except for Ncx1. In this case, two different probes of 689 and $693 \mathrm{bp}$, were made by PCR from partially overlapping parts of exon 1 using primers:

Ncx1F1, AGACTGTGTCGAACCTGACC;

Ncx1R1, TGCTGTTGACTTAGGACCTG, and

Ncx1F2, GATGGGAAAGTGGTCAACTC;

Ncx1R2, CCCAAGACAAGCAATTGAAG, respectively. Both probes gave identical results.

To ensure specificity of probes, experiments were combined with parallel hybridizationshybridisations using probes detecting known expression patterns.

\section{Acknowledgements}

We are very grateful to Andrei Vacaru for help with Western blotting and gifts of materials. We also thank Bart M. Smits for help in the initial setting up of the screen, Dorien Ward-Van Oostwaard for help with cardiomyocyte culture and Johan van Nes for discussions. We thank Antje Brouwer for technical assistance and Jacqueline Deschamps for discussions, and the Hubrecht Imaging Center for supporting the imaging. This work was supported by a grant from the Netherlands government (BSIK program 03038, Stem Cells in Development and Disease).

\section{References}

BECK, F., ERLER, T., RUSSELL, A. and JAMES, R. (1995). Expression of Cdx-2 in the mouse embryo and placenta: possible role in patterning of the extraembryonic membranes. Dev Dyn. 204: 219-227.

BRAAM, S.R., DENNING, C., VAN DEN BRINK, S., KATS, P., HOCHSTENBACH, R., PASSIER, R. and MUMMERY, C.L. (2008). Improved genetic manipulation of human embryonic stem cells. Nat Methods. 5: 389-392.
CHO, C.H., KIM, S.S., JEONG, M.J., LEE, C.O. and SHIN, H.S. (2000). The Na+ $-\mathrm{Ca} 2+$ exchanger is essential for embryonic heart development in mice. $\mathrm{Mol}$ Cells. 10: 712-722.

CHO, C.H., LEE, S.Y., SHIN, H.S., PHILIPSON, K.D. and LEE, C.O. (2003). Partial rescue of the $\mathrm{Na}+\mathrm{-Ca} 2+$ exchanger (NCX1) knock-out mouse by transgenic expression of NCX1. Exp Mol Med. 35: 125-135.

CONWAY, S.J., KRUZYNSKA-FREJTAG, A., WANG, J., ROGERS, R., KNEER P.L., CHEN, H., CREAZZO, T., MENICK, D.R. and KOUSHIK, S.V. (2002). Role of sodium-calcium exchanger (Ncx1) in embryonic heart development: a transgenic rescue? Ann N Y Acad Sci. 976: 268-281.

CONWAY, S.J., KRUZYNSKA-FREJTAG, A., KNEER, P.L., MACHNICKI, M. and KOUSHIK, S.V. (2003). What cardiovascular defect does my prenatal mouse mutant have, and why? Genesis. 35: 1-21.

CSERJESI, P., BROWN, D., LYONS, G.E. and OLSON, E.N. (1995). Expression of the novel basic helix-loop-helix gene eHAND in neural crest derivatives and extraembryonic membranes during mouse development. Dev Biol. 170: 664678.

EBERT, A.M., HUME, G.L., WARREN, K.S., COOK, N.P., BURNS, C.G., MOHIDEEN, M.A., SIEGAL, G., YELON, D., FISHMAN, M.C. and GARRITY, D.M. (2005). Calcium extrusion is critical for cardiac morphogenesis and rhythm in embryonic zebrafish hearts. Proc Natl Acad Sci USA. 102: 17705-17710.

GUILLEMOT, F., NAGY, A., AUERBACH, A., ROSSANT, J. and JOYNER, A.L. (1994). Essential role of Mash-2 in extraembryonic development. Nature. 371 333-336.

HENDERSON, S.A., GOLDHABER, J.I., SO, J.M., HAN, T., MOTTER, C., NGO, A CHANTAWANSRI, C., RITTER, M.R., FRIEDLANDER, M., NICOLL, D.A., FRANK, J.S., JORDAN, M.C., ROOS, K.P., ROSS, R.S. and PHILIPSON, K.D. (2004). Functional adult myocardium in the absence of $\mathrm{Na}+\mathrm{Ca} 2+$ exchange: cardiac-specific knockout of NCX1. Circ Res. 95: 604-611.

IWAMOTO, T., NAKAMURA, T.Y., PAN, Y., UEHARA, A., IMANAGA, I. and SHIGEKAWA, M. (1999). Unique topology of the internal repeats in the cardiac $\mathrm{Na}+/ \mathrm{Ca} 2+$ exchanger. FEBS Lett. 446: 264-268.

IWAMOTO, T., UEHARA, A., IMANAGA, I. and SHIGEKAWA, M. (2000). The $\mathrm{Na}+$ / $\mathrm{Ca} 2+$ exchanger NCX1 has oppositely oriented reentrant loop domains that contain conserved aspartic acids whose mutation alters its apparent $\mathrm{Ca} 2+$ affinity. J Biol Chem. 275: 38571-38580.

KOUSHIK, S.V., BUNDY, J. and CONWAY, S.J. (1999). Sodium-calcium exchanger is initially expressed in a heart-restricted pattern within the early mouse embryo. Mech Dev. 88: 119-122.

KOUSHIK, S.V., WANG, J., ROGERS, R., MOSKOPHIDIS, D., LAMBERT, N.A., CREAZZO, T.L. and CONWAY, S.J. (2001). Targeted inactivation of the sodium-calcium exchanger (Ncx1) results in the lack of a heartbeat and abnormal myofibrillar organization. FASEB J. 15: 1209-1211.

KUIJPER, S., BEVERDAM, A., KROON, C., BROUWER, A., CANDILLE, S. BARSH, G. and MEIJLINK, F. (2005). Genetics of shoulder girdle formation: roles of Tbx15 and aristaless-like genes. Development. 132: 1601-1610.

LANGENBACHER, A.D., DONG, Y., SHU, X., CHOI, J., NICOLL, D.A., GOLDHABER, J.I., PHILIPSON, K.D. and CHEN, J.N. (2005). Mutation in sodium-calcium exchanger 1 (NCX1) causes cardiac fibrillation in zebrafish. Proc Natl Acad Sci USA. 102: 17699-17704.

LUCITTI, J.L., JONES, E.A., HUANG, C., CHEN, J., FRASER, S.E. andnDICKINSON M.E. (2007). Vascular remodeling of the mouse yolk sac requires hemodynamic force. Development. 134: 3317-3326.

LUX, C.T., YOSHIMOTO, M., MCGRATH, K., CONWAY, S.J., PALIS, J. and YODER, M.C. (2008). All primitive and definitive hematopoietic progenitor cells emerging before $\mathrm{E} 10$ in the mouse embryo are products of the yolk sac. Blood. 111: $3435-3438$

LYTTON, J. (2007). Na+/Ca2+ exchangers: three mammalian gene families control Ca2+ transport. Biochem J. 406: 365-382.

MALTSEV, V.A., WOBUS, A.M., ROHWEDEL, J., BADER, M. and HESCHELER, J. (1994). Cardiomyocytes differentiated in vitro from embryonic stem cells developmentally express cardiac-specific genes and ionic currents. Circ Res. 75: $233-244$

NICKERSON, D.A., TOBE, V.O. and TAYLOR, S.L. (1997). PolyPhred: automating the detection and genotyping of single nucleotide substitutions using fluorescence-based resequencing. Nucleic Acids Res. 25: 2745-2751. 
NICOLL, D.A., HRYSHKO, L.V., MATSUOKA, S., FRANK, J.S. and PHILIPSON, K.D. (1996). Mutation of amino acid residues in the putative transmembrane segments of the cardiac sarcolemmal $\mathrm{Na}+-\mathrm{Ca} 2+$ exchanger. J Biol Chem. 271: $13385-13391$.

NICOLL, D.A., OTTOLIA, M., LU, L., LU, Y. and PHILIPSON, K.D. (1999). A new topological model of the cardiac sarcolemmal $\mathrm{Na}+-\mathrm{Ca} 2+$ exchanger. $J \mathrm{Biol}$ Chem. 274: 910-917.

OTTOLIA, M., NICOLL, D.A. and PHILIPSON, K.D. (2005). Mutational analysis of the alpha-1 repeat of the cardiac $\mathrm{Na}(+)-\mathrm{Ca} 2+$ exchanger. J Biol Chem. 280: 1061-1069.

QUEDNAU, B.D., NICOLL, D.A. and PHILIPSON, K.D. (2004). The sodium/calcium exchanger family-SLC8. Pflugers Arch. 447: 543-548.

REUTER, H., HENDERSON, S.A., HAN, T., ROSS, R.S., GOLDHABER, J.I. and PHILIPSON, K.D. (2002). The Na+-Ca2+ exchanger is essential for the action of cardiac glycosides. Circ Res. 90: 305-308.

RHODES, K.E., GEKAS, C., WANG, Y., LUX, C.T., FRANCIS, C.S., CHAN, D.N., CONWAY, S., ORKIN, S.H., YODER, M.C. and MIKKOLA, H.K. (2008). The emergence of hematopoietic stem cells is initiated in the placental vasculature in the absence of circulation. Cell Stem Cell. 2: 252-263.

ROSSANT, J., CROSS, J.C. (2001). Placental development: lessons from mouse mutants. Nat Rev Genet. 2: 538-548.

VAN NES, J., DE GRAAFF, W., LEBRIN, F., GERHARD, M., BECK, F. and DESCHAMPS, J. (2006). The Cdx4 mutation affects axial development and reveals an essential role of $\mathrm{Cdx}$ genes in the ontogenesis of the placental labyrinth in mice. Development. 133: 419-428.

WAKIMOTO, K., KOBAYASHI, K., KURO, O., YAO, A., IWAMOTO, T., YANAKA, N., KITA, S., NISHIDA, A., AZUMA, S., TOYODA, Y., OMORI, K., IMAHIE, H., OKA, T., KUDOH, S., KOHMOTO, O., YAZAKI, Y., SHIGEKAWA, M., IMAI, Y., NABESHIMA, Y. and KOMURO, I. (2000). Targeted disruption of $\mathrm{Na}+/ \mathrm{Ca}+$ exchanger gene leads to cardiomyocyte apoptosis and defects in heartbeat. $J$ Biol Chem. 275: 36991-36998.

WAKIMOTO, K., KURO-O M, YANAKA, N., KOMURO, I., NABESHIMA, Y.I. and IMAI, Y. (2001). Expression of $\mathrm{Na}+\mathrm{Ca}(2+)$ exchanger (NCX1) gene in the developmental mouse embryo and adult mouse brain. Comp Biochem Physiol B Biochem Mol Biol. 130: 191-198. 


\section{Further Related Reading, published previously in the Int. J. Dev. Biol.}

See our recent Special Issue Placenta edited by Joan S. Hunt and Kent L. Thornburg at: http://www.ijdb.ehu.es/web/contents.php?vol=54\&issue=2-3

Creating frog heart as an organ: in vitro-induced heart functions as a circulatory organ in vivo Masayoshi Kinoshita, Takashi Ariizumi, Shinsuke Yuasa, Shunichirou Miyoshi, Shinji Komazaki, Keiichi Fukuda and Makoto Asashima Int. J. Dev. Biol. (2010). 54: 851 - 856. (doi: 10.1387/ijdb.093036mk)

Movement and commitment of primitive streak precardiac cells during cardiogenesis Carmen Lopez-Sanchez, Natividad Garcia-Masa, Carlos M. Gañan and Virginio Garcia-Martinez Int. J. Dev. Biol. (2009) 53: 1445-1455

In vivo forced expression of myocardin in ventricular myocardium transiently impairs systolic performance in early neonatal pig heart

Mario Torrado, Alberto Centeno, Eduardo López and Alexander T. Mikhailov

Int. J. Dev. Biol. (2009) 53: 1457-1467

\section{Lessons from a search for leaf mutants in Arabidopsis thaliana}

José Manuel Pérez-Pérez, Héctor Candela, Pedro Robles, Víctor Quesada, María Rosa Ponce and José Luis Micol Int. J. Dev. Biol. (2009) 53: 1623-1634

The heart forming region of early chick embryo is an alternative source of embryonic stem cells Seema Borgave, Kirti Ghodke and Surendra Ghaskadbi Int. J. Dev. Biol. (2009) 53: 91-99

The enigmatic role of the ankyrin repeat domain 1 gene in heart development and disease Alexander T. Mikhailov and Mario Torrado Int. J. Dev. Biol. (2008) 52: 811-821

Pathways in blood and vessel development revealed through zebrafish genetics.

Philip S Crosier, Maggie L Kalev-Zylinska, Christopher J Hall, Maria Vega C Flores, Julia A Horsfield and Kathryn E Crosier Int. J. Dev. Biol. (2002) 46: 493-502

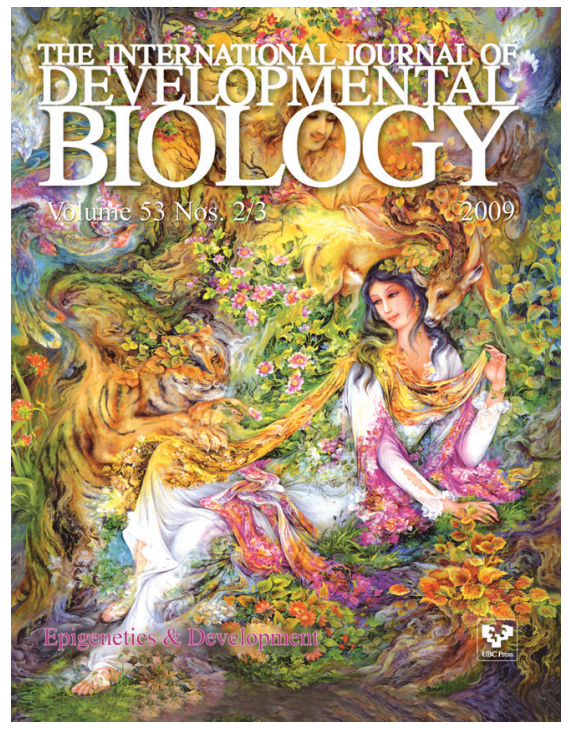

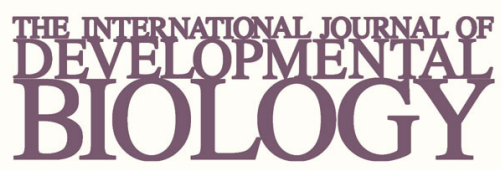

Volume 54 Nos. 6/7

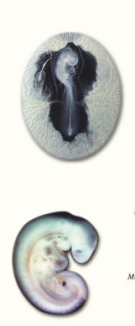

Developmental Hematopoiesis
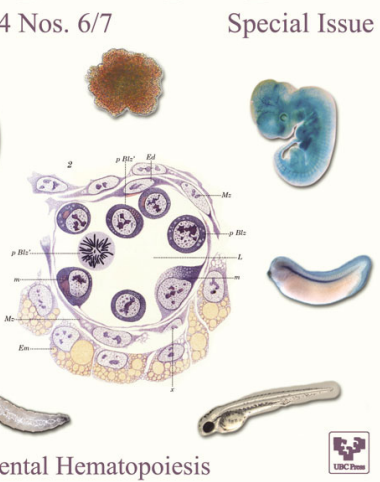

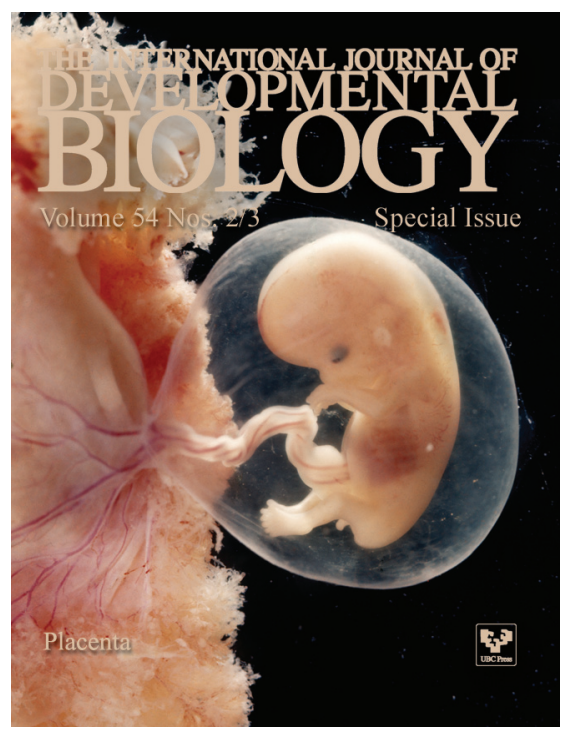

